\title{
ChemComm
}

\section{NHC-Cu(I) catalysed asymmetric conjugate silyl transfer to unsaturated lactones: application in kinetic resolution $\dagger$}

Cite this: Chem. Commun., 2013, 49, 5150

Received 25th March 2013, Accepted 15th April 2013

DOI: $10.1039 / c 3 c c 42160 k$

www.rsc.org/chemcomm

The scope of the asymmetric silyl transfer to unsaturated lactones utilising a $\mathrm{C}_{2}$-symmetric $\mathrm{NHC}-\mathrm{Cu}(\mathrm{I})$ catalyst has been established and kinetic resolutions mediated by silyl transfer have been used to prepare enantiomerically enriched anti-4,5-disubstituted 5-membered lactones. The method has been exploited in an expedient synthesis of (+)-blastmycinone.

The asymmetric conjugate addition of a silicon nucleophile to $\alpha, \beta$-unsaturated carbonyl compounds is a valuable transformation in organic synthesis ${ }^{1}$ as the resulting $\beta$-silyl carbonyl compounds are robust synthetic equivalents of $\beta$-hydroxy carbonyl compounds courtesy of the stereospecific Fleming-Tamao oxidation. ${ }^{2}$ The $\beta$-hydroxy carbonyl moiety is synonymous with the aldol reaction and is a well-known motif: the ability to efficiently generate this valuable motif in stereoselective fashion remains an important goal in modern synthetic chemistry. Fleming's conjugate addition of silyl cuprates to electrondeficient alkenes remained for a long time the method of choice for establishing the $\beta$-silyl carbonyl motif. ${ }^{2 e, 3}$ In the 1980s Hayashi and Ito pioneered the development of asymmetric silylation using palladium catalysis, however narrow substrate scope has limited adoption of the method. ${ }^{4}$ In 2006, Oestreich disclosed an asymmetric conjugate silylation protocol using a $\mathrm{Si}-\mathrm{B}$ reagent $\left(\mathrm{PhMe}_{2} \mathrm{SiBpin}\right)^{1 a, 5}$ in the presence of an enantiomerically pure rhodium catalyst. ${ }^{6}$ In 2010, a complementary protocol from Hoveyda employed $\mathrm{N}$-heterocyclic carbene (NHC) ligands ${ }^{7}$ in $\mathrm{Cu}$ (I)-catalysed asymmetric addition of $\mathrm{PhMe}_{2} \mathrm{SiBpin}$ to $\alpha, \beta$-unsaturated carbonyl systems. ${ }^{8}$ Hoveyda's strategy exploits the use of readily accessible pre-catalysts with inexpensive $\mathrm{Cu}(\mathrm{I})$ salts and thus represents a highly attractive method for asymmetric conjugate silylation. ${ }^{9}$

Although the Oestreich and Hoveyda protocols allow the asymmetric silylation of a wide range of cyclic and acyclic substrates (e.g. esters, ketones, nitriles), limited studies on silyl transfer to heterocyclic systems, and in particular $\alpha, \beta$-unsaturated

School of Chemistry, University of Manchester, Oxford Road, Manchester, M13 9PL, UK. E-mail: david.j.procter@manchester.ac.uk

$†$ Electronic supplementary information (ESI) available. See DOI: 10.1039/ c3cc42160k

$\ddagger$ Contributed equally. lactone substrates, have been described. ${ }^{6,8}$ Furthermore, in general, asymmetric conjugate additions to 5-membered substrates are known to be challenging. ${ }^{10}$ In this Communication we describe our studies to optimise and establish the scope of the Cu-catalysed asymmetric silyl transfer to unsaturated lactones. We also report the kinetic resolution of 5-substituted butenolides ${ }^{11}$ mediated by the silyl transfer.

Building on Oestreich's studies involving furanone $1,{ }^{6 a, c}$ we began our investigation by studying silyl transfer to 1 using Hoveyda's protocol. $^{12}$ Employing L1, a ligand that has previously been used in conjugate silyl transfer to carbocyclic systems (Table 1), ${ }^{8 a}$ poor enantiocontrol was observed in the silylation of 1 (entry 1). Subtle modifications of the $C_{1}$-symmetric imidazolinium salt core did little to improve the outcome (entries 2-5). For furanone 1, enantioselectivities were improved by a switch to $C_{2}$-symmetric ligands (entries 6-10). In particular, the best results were obtained using $C_{2}$-symmetric ligands

Table 1 Screen of NHC-Cu(I) complexes

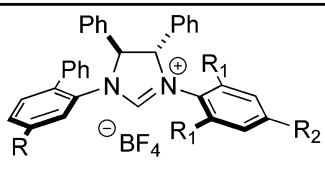

$C_{1}$-symmetric imidazolinium salts L1-L5

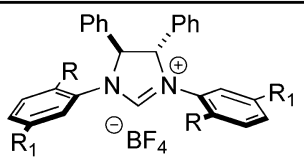

$\mathrm{C}_{2}$-symmetric imidazolinium salts L6-L10

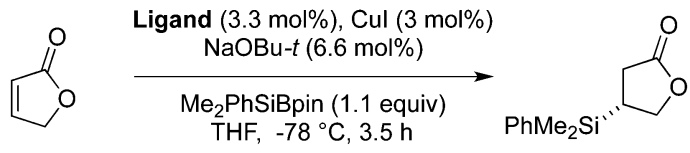

1

\begin{tabular}{lllllll}
\hline Entry & Ligand & Type & $\mathrm{R}$ & $\mathrm{R}_{1}$ & $\mathrm{R}_{2}$ & er \\
\hline 1 & L1 & $C_{1}$ & $\mathrm{Me}$ & $\mathrm{Et}$ & $\mathrm{H}$ & $62: 38$ \\
2 & L2 & $C_{1}$ & $\mathrm{H}$ & $\mathrm{Et}$ & $\mathrm{H}$ & $56: 44$ \\
3 & L3 & $C_{1}$ & $\mathrm{i}-\mathrm{Pr}$ & $\mathrm{Et}$ & $\mathrm{H}$ & $60: 40$ \\
4 & L4 & $C_{1}$ & $\mathrm{H}$ & $\mathrm{Me}$ & $\mathrm{Me}$ & $75: 25$ \\
5 & L5 & $C_{1}$ & $\mathrm{Me}$ & $\mathrm{Me}$ & $\mathrm{Me}$ & $66.5: 33.5$ \\
6 & L6 & $C_{2}$ & $\mathrm{H}$ & $\mathrm{Ph}$ & - & $80.5: 19.5$ \\
7 & L7 & $C_{2}$ & $\mathrm{Me}$ & $\mathrm{Ph}$ & - & $72: 28$ \\
8 & L8 & $C_{2}$ & 2-Naphthyl & $\mathrm{H}$ & - & $93: 7$ \\
9 & L9 & $C_{2}$ & 2-Naphthyl & i-Pr & - & $54: 46$ \\
10 & L10 & $C_{2}$ & 2-Anthryl & $\mathrm{H}$ & - & $92: 8$
\end{tabular}


Table 2 Optimisation of the $\mathrm{Cu}(\mathrm{l})$ source

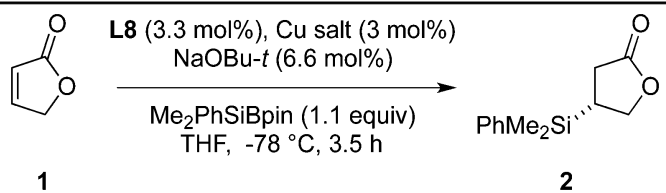

\begin{tabular}{lllll}
\hline Entry & Cu salt & Additive & Conv. (\%) & er \\
\hline 1 & CuCl & - & 71 & $93: 7$ \\
2 & CuBr & - & 80 & $90.5: 9.5$ \\
3 & CuBr.SMe & - & 68 & $89.5: 10.5$ \\
4 & CuOTf & - & 91 & $89.5: 10.5$ \\
5 & CuI & - & $>98$ & $93: 7$ \\
6 & CuI & 4 A MS & $>98$ & $93: 7$ \\
\hline
\end{tabular}

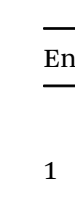

$2^{b}$

3

4
5

6

\section{Entry

Entry

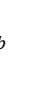

\footnotetext{
${ }^{a}$ Yield of isolated product. ${ }^{b}$ L3 gives a $92: 8$ er, see ref. $8 a$.
}

Importantly, we found that 'glove-box free' conditions could be used thus greatly simplifying operational procedures. With optimised conditions in hand, we applied the protocol to the asymmetric conjugate silylation of 5,6 and 7-membered $\alpha, \beta$-unsaturated lactones (Table 3). The desired $\beta$-silyl adducts were obtained in up to $96.5: 3.5$ er in good yield (entries 1-3). Interestingly, the 8-membered lactone did not react, presumably due to conformational effects (entry 4). When a 7-membered lactone was fused with an aromatic ring, there was a deleterious effect upon enantiocontrol although the yield remained high (entry 5). Moderate selectivity was also observed in the silylation of a 2-substituted lactone (entry 6).

Table 4 Kinetic resolutions mediated by $\mathrm{Cu}(\mathrm{I})-\mathrm{NHC}$ catalysed asymmetric silyl transfer to 5-substituted butenolides

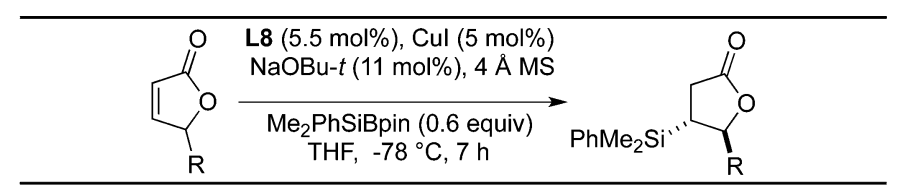

\begin{tabular}{llllll}
\hline Entry & Substrate & Conversion $^{a}(\%)$ & Yield $^{b}(\%)$ & er & $s^{c}$ \\
\hline
\end{tabular}

bearing extended aromatic systems (naphthyl and anthryl, entries 8 and 10) on the $N$-phenyl substituent. However, the presence of additional steric bulk had a detrimental effect on enantioinduction (entry 9). Thus, the use of a $C_{2}$-symmetric ligand $\mathbf{L} \mathbf{8}$ gave the best results in silyl transfer to $\mathbf{1}$.

With ligand choice completed, we turned our attention to further optimising the reaction conditions (Table 2). Although different $\mathrm{Cu}(\mathrm{I})$ sources ${ }^{13}$ did not have a significant effect on

\begin{tabular}{l} 
different $\mathrm{Cu}(\mathrm{I})$ sources ${ }^{13}$ did not have a significant effect on \\
enantioinduction, copper salt selection was important in max- \\
imizing conversions due to their moisture sensitivity. \\
In this sense, the use of CuI gave the best results (entry 5) \\
and the addition of molecular sieves improved reproducibility. \\
Table $3 \mathrm{Cu}(\mathrm{I})-\mathrm{NHC}$ catalysed asymmetric silyl transfer to unsaturated lactones \\
\hline Entry \\
\hline Lactone
\end{tabular}

\begin{tabular}{l} 
different $\mathrm{Cu}(\mathrm{I})$ sources ${ }^{13}$ did not have a significant effect on \\
enantioinduction, copper salt selection was important in max- \\
imizing conversions due to their moisture sensitivity. \\
In this sense, the use of CuI gave the best results (entry 5$)$ \\
and the addition of molecular sieves improved reproducibility. \\
Table $3 \mathrm{Cu}(\mathrm{I})$-NHC catalysed asymmetric silyl transfer to unsaturated lactones \\
\hline Entry
\end{tabular}

In this sense, the use of CuI gave the best results (entry 5)
dhe addition of molecular sieves improved reproducibility.
antioinduction, copper salt selection was important in max-
izing conversions due to their moisture sensitivity.

\begin{tabular}{l} 
different $\mathrm{Cu}(\mathrm{I})$ sources ${ }^{13}$ did not have a significant effect on \\
enantioinduction, copper salt selection was important in max- \\
imizing conversions due to their moisture sensitivity. \\
In this sense, the use of CuI gave the best results (entry 5) \\
and the addition of molecular sieves improved reproducibility. \\
Table $3 \mathrm{Cu}(\mathrm{I})-\mathrm{NHC}$ catalysed asymmetric silyl transfer to unsaturated lactones \\
\hline Entry \\
\hline Lactone
\end{tabular}

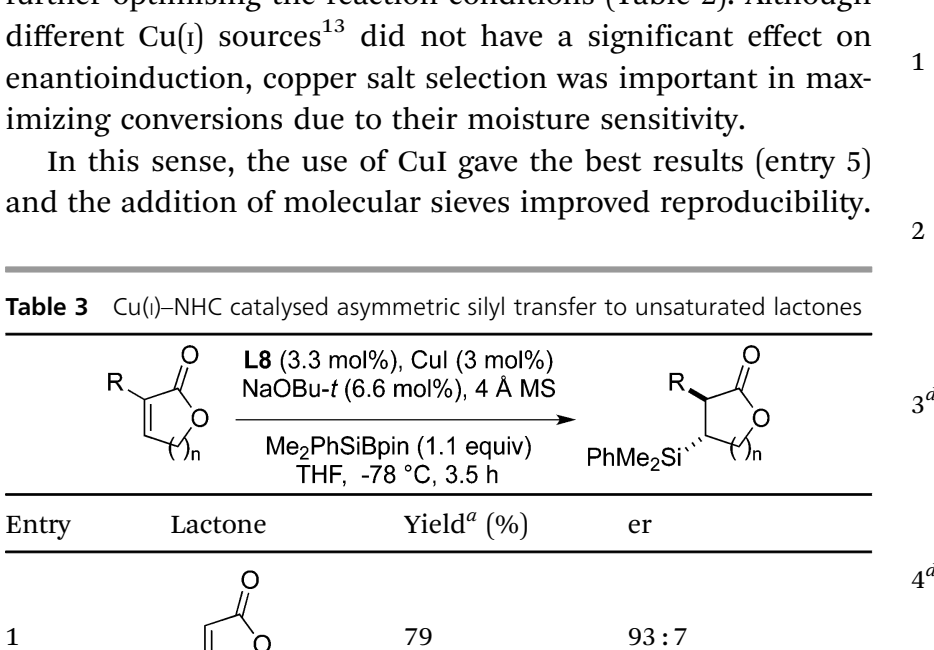

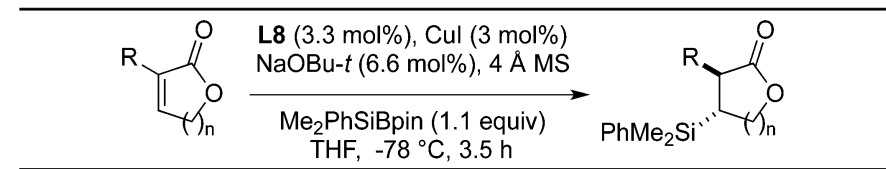

ther optimising the reaction conditions (Table 2). Although
In this sense, the use of $\mathrm{CuI}$ gave the best results (entry 5)
the addition of molecular sieves improved reproducibility.
zing conversions due to their moisture sensitivity.
sources ${ }^{13}$ did not have a significant effect on
$3 \mathrm{Cu}(\mathrm{I})-\mathrm{NHC}$ catalysed asymmetric silyl transfer to unsaturated lactones 2 \begin{tabular}{ccc} 
& THF, $-78{ }^{\circ} \mathrm{C}, 3.5 \mathrm{~h}$ & \\
Lactone & Yield $^{a}(\%)$ & er \\
\hline 0 &
\end{tabular} $3^{d}$<smiles>CC1C=CC(=O)O1</smiles>

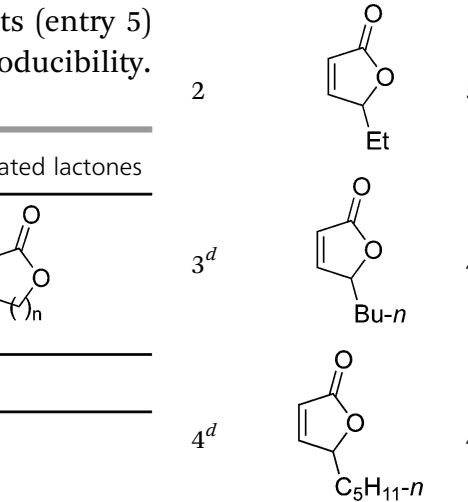
$93: 7: 9.5$

\section{fact}




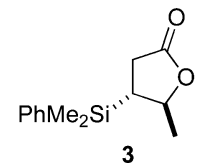
$\stackrel{\text { i) LDA ( } 1.5 \text { equiv), }-78{ }^{\circ} \mathrm{C} 1 \mathrm{~h}}{\text { ii) } n \text {-Bul (3 equiv), DMPU ( } 1.5 \text { equiv) }}$
$-78{ }^{\circ} \mathrm{C}$ to rt, $18 \mathrm{~h}, 73 \%$

89:11 er
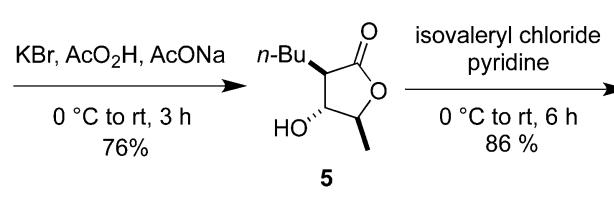

$\%$

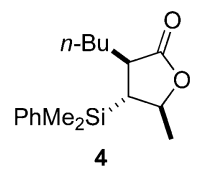

4

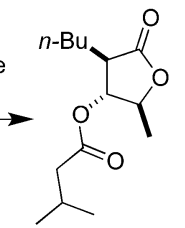

(+)-blastmycinone

Scheme 1 Catalytic asymmetric approach to (+)-blastmycinone

To further explore the scope of the protocol, the kinetic resolution of a series of 5-substituted butenolides was carried out using $\mathrm{Cu}(\mathrm{I})-\mathrm{NHC}$ catalysed asymmetric silyl transfer. ${ }^{14}$ Pleasingly, treatment of 5-substituted butenolides with $60-70 \mathrm{~mol} \%$ of $\mathrm{PhMe}_{2} \mathrm{SiBpin}$ and the $C_{2}$-symmetric catalyst derived from $\mathbf{L 8}$ and CuI afforded silylated products after kinetic resolution in good yields (up to a maximum of 50\%), good enantiomeric ratios and as single anti-diastereoisomers (Table 4). ${ }^{15}$

The rate of addition to 5-substituted butenolides was slower than silyl transfer to unsubstituted lactones, presumably due to increased steric hindrance, therefore higher catalyst and silylborane loading was required. ${ }^{17}$ Primary alkyl, allyl, benzyl and phenyl substituents at the 5-position of butenolides were found to be compatible with the process. To our knowledge, these examples represent the first kinetic resolutions achieved by $\mathrm{Cu}$-catalysed silyl transfer from a $\mathrm{Si}-\mathrm{B}$ reagent.

To demonstrate the value of $\mathrm{Cu}(\mathrm{I})-\mathrm{NHC}$ catalysed asymmetric silyl transfer to unsaturated lactones, we report a concise approach to (+)-blastmycinone, a natural product arising from the hydrolysis of the antibiotic (+)-antimycin $\mathrm{A}_{3}$ (Scheme 1). ${ }^{18}$ Alkylation of silylated lactone 3 (see entry 1, Table 4 ) provided 4 with three contiguous stereocenters as a single diastereoisomer. Fleming-Tamao oxidation ${ }^{2}$ then gave lactone 5, which after esterification afforded (+)-blastmycinone. ${ }^{19}$

In summary, we have explored the scope of a convenient procedure for asymmetric silyl transfer to unsaturated lactones. The $\mathrm{Cu}(\mathrm{I})-\mathrm{NHC}$ catalysed process delivers $\beta$-silylated lactones in good yields and enantioselectivities. In contrast to observations with other substrate classes, the use of $C_{2}$-symmetric imidazolinium salts as NHC precursors was crucial for efficient asymmetric silyl transfer to unsaturated 5-membered lactones. Kinetic resolution using $\mathrm{Cu}$-catalysed silyl transfer from a $\mathrm{Si}-\mathrm{B}$ reagent has been applied to racemic 5-butenolides and affords products with good enantiocontrol and excellent diastereocontrol. The method has been used in an expedient asymmetric synthesis of (+)-blastmycinone.

We thank The Leverhulme Trust (V.P.) and the EPSRC (J.P.R.) for funding and Robyn Bullough for assistance optimising the conversion of 3-5.

\section{Notes and references}

1 For selected reviews, see: (a) M. Oestreich, E. Hartmann and M. Mewald, Chem. Rev., 2013, 113, 402; (b) E. Hartmann, D. J. Vyas and M. Oestreich, Chem. Commun., 2011, 47, 7917; (c) M. Suginome and Y. Ito, Chem. Rev., 2000, 100, 3221; (d) E. Hartmann and M. Oestreich, Chim. Oggi, 2011, 29, 34.

2 (a) I. Fleming, R. Henning and H. Plaut, J. Chem. Soc., Chem. Commun., 1984, 29; (b) I. Fleming and P. E. J. Sanderson, Tetrahedron Lett., 1987, 28, 4229; (c) K. Tamao, N. Ishida, T. Tanaka and M. Kumada, Organometallics, 1983, 2, 1694; (d) K. Tamao, T. Tanaka, T. Nakajima, R. Sumiya, H. Arai and Y. Ito, Tetrahedron Lett., 1986, 27, 3377; (e) I. Fleming, A. Barbero and D. Walter, Chem. Rev., 1997, 97, 2063; $(f)$ I. Fleming, in Science of Synthesis, ed. I. Fleming, Thieme, Stuttgart, 2002, vol. 4, pp. 927-946.

3 For other approaches to racemic $\beta$-silyl carbonyls see: (a) L. Iannazzo and G. A. Molander, Eur. J. Org. Chem., 2012, 4923; (b) B. H. Lipshutz, J. A. Sclafani and T. Takanami, J. Am. Chem. Soc., 1998, 120, 4021; (c) G. Auer, B. Weiner and M. Oestreich, Synthesis, 2006, 2113; (d) H. Ito, T. Ishizuka, J.-i. Tateiwa, M. Sonoda and A. Hosomi, J. Am. Chem. Soc., 1998, 120, 11196; (e) C. T. Clark, J. F. Lake and K. A. Scheidt, J. Am. Chem. Soc., 2004, 126, 84; $(f)$ M. Oestreich and B. Weiner, Synlett, 2004, 2139.

4 (a) T. Hayashi, Y. Matsumoto and Y. Ito, J. Am. Chem. Soc., 1988, 110, 5579; (b) Y. Matsumoto, T. Hayashi and Y. Ito, Tetrahedron, 1994, 50, 335.

5 For a review of Si-B chemistry, see: T. Ohmura and M. Suginome, Bull. Chem. Soc. Jpn., 2009, 82, 29.

6 (a) C. Walter, G. Auer and M. Oestreich, Angew. Chem., Int. Ed., 2006, 45, 5675; (b) C. Walter and M. Oestreich, Angew. Chem., Int. Ed., 2008, 47, 3818; (c) C. Walter, R. Fröhlich and M. Oestreich, Tetrahedron, 2009, 65, 5513.

7 For NHCs in metal catalysis, see: (a) S. Díez-González, N. Marion and S. P. Nolan, Chem. Rev., 2009, 109, 3612; (b) S. Díez-González and S. P. Nolan, Aldrichimica Acta, 2008, 41, 43; (c) F. Glorius, Topics in Organometallic Chemistry, $\mathrm{N}$-Heterocyclic Carbenes in Transition Metal Catalysis, Springer-Verlag, Berlin, Heidelberg, 2006, vol. 21, pp. 1-218.

8 (a) K.-S. Lee and A. H. Hoveyda, J. Am. Chem. Soc., 2010, 132, 2898; (b) K.-S. Lee, H. Wu, F. Haeffner and A. H. Hoveyda, Organometallics, 2012, 31, 7823; For a metal-free catalytic C-Si bond formation, see: J. M. O'Brien and A. H. Hoveyda, J. Am. Chem. Soc., 2011, 133, 7712. 9 For alternative asymmetric approaches to $\beta$-silyl carbonyl compounds, see: (a) I. Ibrahem, S. Santoro, F. Himo and A. Córdova, Adv. Synth. Catal., 2011, 353, 245; (b) A. Welle, J. Petrignet, B. Tinanat, J. Wouters and O. Riant, Chem.-Eur. J., 2010, 16, 10980; (c) B. H. Lipshutz, N. Tanaka, B. R. Taft and C.-T. Lee, Org. Lett., 2006, 8, 1963; (d) R. Shintani, K. Okamoto and T. Hayashi, Org. Lett., 2005, 7, 4757; (e) M. A. Kacprzynski, S. A. Kazane, T. L. May and A. H. Hoveyda, Org. Lett., 2007, 9, 3187. 10 (a) S. Kehrli, D. Martin, D. Rix, M. Mauduit and A. Alexakis, Chem.-Eur. J., 2010, 16, 9890; (b) D. Martin, S. Kehrli, M. d'Augustin, H. Clavier, M. Mauduit and A. Alexakis, J. Am. Chem. Soc., 2006, 128, 8416; (c) L. Liang, T. T.-L. Au-Yeung and A. S. C. Chan, Org. Lett., 2002, 4, 3799.

11 (a) For a reductive dynamic kinetic resolution of similar substrates, see: M. P. Rainka, J. E. Milne and S. L. Buchwald, Angew. Chem., Int. $E d ., 2005,44,6177$; (b) For kinetic resolutions of similar substrates using organolithiums, see: S. H. Lim and P. Beak, Org. Lett., 2002, 4, 2657.

12 For a preliminary result, see: H. Y. Harb, K. D. Collins, J. V. G. Altur, S. Bowker, L. Campbell and D. J. Procter, Org. Lett., 2010, 12, 5446.

13 The use of CuCN was ineffective.

14 (a) For the kinetic resolution of racemic 1-alkyl-2-methylenecyclopropanes using $\mathrm{PhMe}_{2} \mathrm{SiBpin}$ and Pd-catalysis, see: T. Ohmura, H. Taniguchi and M. Suginome, Org. Lett., 2009, 11, 2880; (b) For the two-directional desymmetrization of $\alpha, \beta$-unsaturated esters using $\mathrm{PhMe}_{2} \mathrm{SiBpin}$ and Rh-catalysis, see: E. Hartmann and M. Oestreich, Org. Lett., 2012, 14, 2406.

15 I. Fleming, N. L. Reddy, K. Takaki and A. C. Ware, J. Chem. Soc., Chem. Commun., 1987, 1472.

16 (a) E. Vedejs and M. Jure, Angew. Chem., Int. Ed., 2005, 44, 3974; (b) H. B. Kagan and J. C. Fiaud, Top. Stereochem., 1988, 18, 249.

17 Iso-propyl 5-substituted butenolide resulted in low conversion (ca. 10\%) but good enantiocontrol (er 87: 13). Attempted addition to the analogous tert-butyl substituted lactone resulted in no conversion.

18 M.-J. Chen, C.-Y. Lo, C.-C. Chin and R.-S. Liu, J. Org. Chem., 2000, 65, 6362.

19 R. S. Ferrarini, A. A. Dos Santos and J. V. Comasseto, Tetrahedron, 2012, 68, 10601 and references cited therein. 